\title{
Publishing Company Operating Performance Evaluation Before and After the IPO
}

\author{
Rong Yang \\ Department of Finance and Accounting, Beijing Institute of Graphic Communication, Daxing, Beijing, China
}

\begin{abstract}
The main purpose of the publishing companies' IPO is to ensure maintenance and appreciation of the value of national capital. Evaluating listed publishing companies whether in reality to realize above goal is the starting point of writing in this paper. This paper, by using the announcement of information of the three listed publishing companies, which are Central South Media(601098), Publishing Media(601999) and Phoenix Media(601928), uses enterprise economic value added rate, the performance evaluation methods in the financial field to study above problem. Though the study on operation and financial data of publishing companies, the results showed that economic value added rate of listed publishing companies remains to be further improved and managers still have some behavior of damaging the interests of stockholders. Listed publishing companies should actively expand investment channels and change the situation of holding too much cash, meanwhile should further improve the management of inventory books and reduce the risk of stock price actually. Last but not least, listed publishing companies should also actively broaden the financing channels, increasing the financial leverage, to Improve the value of enterprises.
\end{abstract}

Keywords - IPO, enterprise value, economic value added, economic value added rate

\section{出版上市公司 IPO 前后经营绩效评价}

\author{
杨荣 \\ 北京印刷学院经济管理学院财务会计系, 大兴, 北京, 中国
}

摘 要 出版企业进行 IPO 上市资本运营的主要目的是确保资本的保值增值，现实中出版上市公司是否实现了上述目标是本文写作 的出发点。本文利用出版传媒、中南传媒和风凰传媒 3 家出版上市公司的公告资料, 运用财务领域企业经济增加值率的绩效评价方法 对上述问题进行研究。通过对出版企业经营情况和财务数据的考察发现, 出版上市企业的经济增加值率仍有待进一步提高, 出版上市 企业还存在损害股东权益价值的经营行为。研究结果显示, 出版上市公司应积极拓展投资渠道, 改变现金持有过多的局面; 同时, 应 进一步改善库存图书的管理, 切实降低存货跌价风险; 最后, 还应积极拓宽融资渠道, 适当提高财务杜杆率, 以提高出版企业的价值。

关键词 IPO 上市, 企业价值, 经济增加值, 经济增加值率

\section{1. 引言}

最近几年，出版企业资本运营与 IPO 上市成为行业中 的热点问题。出版企业上市运作是资本运营中非常重要的 一环，通过股票上市进行资本运营，可以促进企业建立现 代企业制度, 改善公司治理结构, 开展数字化业务转型和 多元化转型, 有效提高企业的经营绩效, 实现企业资本的 保值增值。目前有 3 家原先主营图书出版业务的出版集团 实现了 IPO 上市, 这 3 家出版上市公司在上市之后的经营 绩效如何，是否实现了资本的保值增值，对其他出版企业
有何借鉴, 无疑应成为业界关心的问题。本文利用出版传 媒、中南传媒和风凰传媒 3 家出版上市公司的公告资料, 通过财务领域企业经济增加值率的绩效评价方法, 对上述 问题进行观察。

\section{2. 文献回顾}

关于经济增加值的文献研究有很多, 但关于出版企业 经济增加值的研究则较少。本文从上述两个方面进行文献 回顾。

北京印刷学院校级项目“中国出版业上市公司资本运营战略分析及绩效研究”（23190112048） 


\section{1 关于经济增加值的研究}

关于企业经营绩效的衡量方法, 学术界普遍认为会计 数据中的盈利水平指标不足以完全反映企业的经营绩效, 并且会计指标被认为操纵的问题也常为人诟病。基于此, 本文使用经济增加值 (Economic Value Added, EVA) 作为 企业经营绩效的衡量标准。该指标的有效性不会受制于股 票市场的发育程度; 同时能显著降低有关会计数据被认为 操纵的可能, 而且更为重要的是, 相比于一般的会计数据 指标, 经济增加值指标能充分考虑股权资本的机会成本, 使得计算结果更能体现股东价值的增加与否。

国外学者对 EVA 的研究, 从理论到实证均进行了深入 的研究, 20 世纪 90 年代后期, 对 EVA 的关注点主要是与 传统业绩评价指标的比较, EVA 是否更能解释公司价值的 变动, 如 Stephen O'Byrne (1996)、Wallace (1996)、Shimin Chen 和 James L. Dodd（1997）、Rajan S.R.（1999）等。他 们的研究成果均显示出以 EVA 作为业绩评价标准的企业价 值增值更加显著, EVA 与企业价值的相关性明显高于其他 传统业绩评价指标与企业价值的相关性。近来, 对 EVA 的 应用更加多样, 主要有不同企业之间的 EVA 比较 (Ismail Issham, 2008 ); 长期中 EVA 与股票价值之间的关系 (Mohammas, 2010) 等。

EVA企业业绩评价自 1993 年首次引入国内就引起了学 者广泛的关注, 2010 年, 国资委宣布将对央企实施 EVA 业 绩考核方式, 学术界对 EVA 的研究又掀起一轮新的热潮。 早期学者对 EVA 的研究主要集中于 EVA 的简单应用, 后来 增加了 EVA 与传统指标在解释企业价值方面的比较, 如乔 华、张双全（2001）、孔军华、王喜刚（2003）、郭家虎和 崔文娟 (2004)。同时, 另一些学者对 EVA 的使用提出了 质疑, 如王化成、程小可 (2004) 认为 EVA 繁杂的计算相 对于研究结果而言得不偿失; 田育新 (2007) 的研究结果 则显示出 EVA 在我国的适用性还有待考察。

\section{2 关于出版企业资本运营绩效的研究}

学术界对出版企业业绩评价方面的研究较少, 王海云、 刘益、付海燕（2007）、王关义（2009）、尹章池（2011）、 文鹏、王亚琼（2012）主要关注出版单位绩效考核指标的 构建, 研究的出发点在于出版社内部。唐溯（2010）则针 对出版上市公司进行了绩效评价, 但没有将经营绩效与企 业价值联系起来。另外, 学术界关于资本运营的绩效则更 少涉及。

\section{3. 样本的选取、数据来源与经济增加值率计算方法}

\section{1 样本选取与数据}

在国家对出版传媒行业一系列支持鼓励政策的背景之
下, 出版传媒 (601999) 开启首例 IPO 上市后, 多家出版 企业借鉴其经验开始上市。其中, 以 IPO 上市的有, 出版 传媒（601999）、中南传媒（601098）、凤凰传媒（601928）。 上述上市公司为我们研究出版企业资本运营绩效问题提供 了丰富的素材。本文就以上述 3 家出版上市公司作为样本, 收集相关数据研究出版上市公司资本运营绩效问题。

由于出版上市公司的上市时间不同，本文选取上市之 后首年至 2013 年年报作为截至点, 研究上市之前后的绩效 变动, 对比上市公司 $\mathrm{EVA}$ 绩效改善的程度。本文的数据来 源为国泰安 CSMAR 数据库和巨潮网企业公告。

\section{2 出版上市公司 EVA 绩效评价计算方法}

经济增加值（EVA）指标的经济学含义是指上市企业 在扣除了投资者的机会成本后所创造的价值。经济增加值 （EVA）指标在财务领域已经相当成熟, 主要是税后净营 业利润减去投入的资本成本得到。由于税后净营业利润不 是报表中直接报出的, 需要使用利润表中的一些项目进行 计算调整。同时, 资本成本也不是报表上直接报出的, 而 是由企业投入资本乘以相应的资本成本率得出。企业投入 资本包括债权人投入企业的债务资本，和股东投入企业的 股权资本，相应的资本成本率也包括债务资本成本率和股 权资本成本率。

经济增加值 $(\mathrm{EVA})=$ 税后净营业利润-资本使用成本 (1)

资本使用成本 $=($ 债务资本 + 股权资本 + 约当股权资本 $)$ $\times$ 加权平均资本成本率

债务资本 $=$ 短期借款 + 一年内到期的长期借款 + 长期借 款 + 应付债券

股权资本 $=$ 股东权益合计 + 少数股东权益 + 约当股权资 本

加权平均资本成本率 $=$ 债务资本成本率 $\times$ (债务资本市 值/总市值） $\times(1$-所得税税率 $)+$ 股权资本成本率 $\times$ （股本 资本市值/总市值)

其中, 债务资本成本率取当年 $3 \sim 5$ 年期中长期银行贷 款基准利率; 股本资本成本率则由如下公式得出:

股本资本成本率 $=$ 无风险收益率 + BETA 系数 $\times$ 市场风 险溢价

其中, 无风险收益率取自上海证交所交易的当年最长 期的国债年收益率; BETA 系数则取各出版上市公司从上市 初始的周收益率与相对应的大盘周收益率进行线性回归得 出, 这些数据均来自于国泰安 CSMAR 数据库; 市场风险 溢价则参照相关研究文献的结果, 如胡小明和冯军 (2014) 计算出近十年来, 沪深 300 指数的平均超额风险收益率 (MRP) 为 6.8\%, 邵希娟、李雅馨和罗箫娜（2013）的研 
究结果显示出中国股票市场的风险溢价为 $5.34 \%$, 石一兵 (2010) 的研究结果则为 $7.75 \%$ 。综合上述研究成果, 本 文使用 $6.63 \%$ 的风险溢价水平。

\section{3 经济增加值率的计算}

由于上述计算过程只能得到个别企业价值增加的绝对 值, 无法将其在行业内进行横向比较。因此, 本文还将各 个企业的经济增加值除以上一年度末各自企业的资产总值 (ASSET) 进行标准化处理得到经济增加值率 (REVA), 用以衡量企业每一元资产所创造的经济增加值。经济增加 值率指标不仅有利于进行同一企业的纵向比较, 也有利于 不同企业之间的横向比较。

$$
\operatorname{REVA}_{i, t}=E V A_{i, t} / \operatorname{ASSET}_{i, t}
$$

\section{4. 实证结果与分析}

\section{1 实证结果列示}

根据经济增加值的计算公式, EVA 值为正, 表明其创 造了价值, EVA 值越高, 表明其创造的价值越多, EVA 的 正负、高低与公司的规模以及经营状况有密切的关系。

下列表格中报告了 3 家出版上市公司从上市前一年至 2013 年为止的经济增加值、经济增加值率、股东权益报酬 率的数值。由于股东权益报酬率是会计利润计算出的股东 财富增值程度, 表中加入股东权益报酬率指标, 可以更加 鲜明地反映出出版企业真实的资本增值程度。

表 12006 至 2013 年出版传媒（601999）经济增加值及经济增加 值率变动

\begin{tabular}{|l|c|c|c|}
\hline & REVA(\%) & $\begin{array}{c}\text { EVA } \\
\text { (万元) }\end{array}$ & ROE (\%) \\
\hline 2006 (上市前一年) & $2.89 \%$ & 3175 & $19.88 \%$ \\
\hline 2007 (上市第一年) & $-3.37 \%$ & -6653 & $16.44 \%$ \\
\hline 2008 (上市第二年) & $-3.59 \%$ & -7248 & $8.62 \%$ \\
\hline 2009 (上市第三年) & $-0.57 \%$ & -3132 & $9.15 \%$ \\
\hline 2010 (上市第四年) & $-3.23 \%$ & -10432 & $8.51 \%$ \\
\hline 2011 (上市第五年) & $-5.73 \%$ & -16487 & $4.23 \%$ \\
\hline 2012 (上市第六年) & $-6.09 \%$ & -18620 & $16.04 \%$ \\
\hline 2013 (上市第七年) & $-5.60 \%$ & -18083 & $4.18 \%$ \\
\hline
\end{tabular}

注: 2006 年股东权益报酬率是用 2006 年的净利润除以 2006 年所 有者权益期末余额计算。
表 1 中报告了出版传媒（601999）上市运作之前一年 至 2013 年的经济增加值率、经济增加值以及股东权益报酬 率的变动情况。06 年出版传媒的经济增加值率为 $2.89 \%$, 经济增加值为 31746626.84 元, 反映出企业能为股东创造出 新的价值, 且每 100 元资产能创造出 2.89 元的价值。虽然 股东权益报酬率显示企业在 2007 年上市后, 股东一直有正 的回报, 但经济增加值一直负值, 这一情况说明出版传媒 上市之后没有实现资本的保值增值。

表 22009 至 2013 年中南传媒（601098）经济增加值率变动

\begin{tabular}{|c|c|c|c|}
\hline & REVA(\%) & $\begin{array}{c}\text { EVA } \\
\text { (万元) }\end{array}$ & ROE (\%) \\
\hline 2009 (上市前一年) & $4.26 \%$ & 23908 & $18.06 \%$ \\
\hline 2010 (上市第一年) & $-0.89 \%$ & -8618 & $16.97 \%$ \\
\hline 2011 (上市第二年) & $-0.84 \%$ & -9178 & $10.73 \%$ \\
\hline 2012 (上市第三年) & $-0.13 \%$ & -1593 & $19.99 \%$ \\
\hline 2013 (上市第四年) & $0.11 \%$ & 1385 & $12.50 \%$ \\
\hline
\end{tabular}

注: 2009 年股东权益报酬率是用 2009 年的净利润除以当年所有 者权益期末余额计算。

表 2 报告了中南传媒上市前一年 2009 年至 2013 年的 经济增加值率、经济增加值以及股东权益报酬率的变动情 况。即使在上市后的四年中中南传媒的股东权益报酬率始 终在 $10 \%$ 以上, 但中南传媒的经济增加值均为负, 直到第 四年 2013 年经济增加值才变为正。上述情况反映出中南传 媒在上市之初没有给股东创造价值, 即使第四年经济增加 值变为正, 经济增加值率也仅 $0.11 \%$, 这显示出资本保值 增值幅度有限。

表 3 凤凰传媒（601928）经济增加值率变动

\begin{tabular}{|c|c|c|c|}
\hline & $\operatorname{REVA}(\%)$ & $\begin{array}{c}\text { EVA } \\
\text { (万元) }\end{array}$ & ROE (\%) \\
\hline 2010 (上市前一年) & $8.56 \%$ & 65169 & $16.38 \%$ \\
\hline 2011 (上市第一年) & $5.23 \%$ & 64583 & $16.62 \%$ \\
\hline 2012 (上市第二年) & $5.91 \%$ & 78546 & $18.78 \%$ \\
\hline 2013 (上市第三年) & $6.56 \%$ & 95087 & $11.10 \%$ \\
\hline
\end{tabular}

注： 2010 年股东权益回报率是用 2010 年净利润除以当年所有者 权益期末余额计算。

表 3 报告了凤凰传媒上市运作之前一年至 2013 年底的 经济增加值率、经济增加值以及股东权益报酬率的变动情 
况。凤凰传媒在上市前一年的经济增加值率为 $8.56 \%$, 上 市第一年为 $5.23 \%$, 第二年为 $5.91 \%$, 第三年为 $6.56 \%$ 。在 这三家上市的样本公司中, 凤凰传媒的企业价值增加表现 最好, 反映出该企业的经营者为股东带来资本的保值增值。

\section{2 实证结果的原因分析}

从上述实证结果中, 我们可以看出 3 家出版上市公司 中, 凤凰传媒实现了资本的保值增值, 而出版传媒和中南 传媒的表现则相对较差。究其原因, 主要有以下三个原因:

第一, 出版上市企业的委托理财业务妨害了资本保值 增值。因为经济增加值计算模型中的利润是税后净营业利 润, 是所有投资者可得的税后总收入, 包括债务人可以获 得的利息。因此, 在计算税后净营业利润概念时, 付给债 权人的利息是要加回到利润表中的营业利润之上的。如果 企业债权人获得利息收入越高, 则企业的财务费用也就越 高, 最终企业的税后净营业利润也就越多。从企业价值角 度看, 企业能给债权人创造价值, 也就能给股东创造价值, 这也就是有时候企业借债并不是坏事的原因。对比 3 家上 市公司的财务费用的情况, 可以发现, 3 家上市公司的财务 费用均为负, 这说明 3 家出版上市公司非但没有借债, 还 因为募集资金存在银行没有进行投资, 以及用自有资金进 行委托理财业务等获得了大量的利息收入。因此, 在税后 净营业利润的计算过程中, 负的财务费用实际上减少了税 后净营业利润。

表 4 出版传媒、中南传媒和凤凰传媒的财务费用 单位: 万元

\begin{tabular}{|c|c|c|c|}
\hline & 出版传媒 & 中南传媒 & 凤凰传媒 \\
\hline 2006 & -92.41 & - & - \\
\hline 2007 & 485.43 & - & - \\
\hline 2008 & -1765.04 & - & - \\
\hline 2009 & -1399.94 & -895.86 & - \\
\hline 2010 & -1261.25 & -1542.97 & -3667.28 \\
\hline 2011 & -1592.24 & -15204.16 & -4344.53 \\
\hline 2012 & -2485.51 & -18393.01 & -19323.46 \\
\hline 2013 & -2910.21 & -18947.2 & -18694.03 \\
\hline
\end{tabular}

注：中南传媒和风凰传媒上市前财务费用因无公开资料不可得。

表 4 中显示了 3 家出版上市公司财务费用情况, 可以 发现, 这 3 家上市公司均存在大量利息收入的情况。企业 的经营目标应该是最大化股东价值, 企业应该积极投资, 创造利润。如果企业不仅不借债, 还把大量的现金存放在
银行, 只收取固定的利息, 这一状况实际上损害了股东的 利益。结果很明显, 即企业经济增加值较低。

第二，大额存货跌价准备提高了企业投入资本数量， 降低了经济增加值。经济增加值模型中投入资本除了包括 债务资本和股本资本之外, 还有约当股权资本。约当股权 资本的主要内容有坏账准备、存货跌价准备、长短期投资/ 委托贷款减值准备、固定资产/无形资产减值准备等。这些 当年计提的上述准备账户余额, 从资产角度看减低了资产 的价值, 也就是减低了投资资本的价值, 但由于其是人为 估计数, 因此在计算投入资本时要加回来。因此, 当企业 的各项减值准备账户数额越大时, 企业投入资本的数量也 越大。

表 5 出版传媒、中南传媒和风凰传媒的存货跌价准备账户余额

\begin{tabular}{|c|c|c|c|}
\hline & 出版传媒 & 中南传媒 & 凤凰传媒 \\
\hline 2006 & 3840.70 & - & - \\
\hline 2007 & 3503.87 & - & - \\
\hline 2008 & 4499.19 & - & - \\
\hline 2009 & 4630.81 & 8264.11 & - \\
\hline 2010 & 4850.36 & 11004.11 & 30340.98 \\
\hline 2011 & 5237.61 & 12574.97 & 37469.13 \\
\hline 2012 & 5844.62 & 17095.90 & 41799.42 \\
\hline 2013 & 7789.86 & 22059.09 & 47259.98 \\
\hline
\end{tabular}

注: 中南传媒和风凰传媒上市前存货跌价准备账户余额因无公开 资料不可得。

由于出版企业经营的特点, 存货跌价准备是各项准备 账户中最重要的一项, 反映了出版企业图书出版的质量和 后期利润实现的质量。表 5 中显示了 3 家出版上市公司的 存货跌价准备账户的余额, 可以发现, 这 3 家上市公司的 存货均出现了数额较为巨大的减值。这一方面说明目前出 版社经营过程图书出版质量还不高, 未来可能影响企业利 润的收回, 另一方面, 大量的存货跌价实际上也损害了经 济增加值的增加。

第三, 负债率较低, 自有资本投资比例较高, 增大了 资本成本，降低了经济增加值。根据加权平均资本成本的 计算公式, 加权平均资本成本的高低与债务资本成本、债 务资本市值与总市值的比值、所得税的税率、股权资本成 本的大小以及股权资本市值与总市值的比值等因素关系较 大。由于整个出版行业一直享有政府给予的免征所得税的 税收优惠, 同时, 股本资本成本率由无风险收益率、BETA 
系数和市场风险溢价共同决定, 而上述三个因素仅与中国 整体金融市场情况相关, 因此, 出版企业的加权平均资本 成本的高低与债务资本市值占总市值的比例以及股权资本 占总市值的比例相关。如果债务资本市值比例较高, 则在 整体长期银行贷款利率偏低的情况下, 加权平均资本成本 率也较低, 从而经济增加值的计算结果较高。

表 62013 年出版传媒、中南传媒与风凰传媒加权平均资本成本率 的构成

\begin{tabular}{|c|c|c|c|}
\hline & 出版传媒 & 中南传媒 & 凤凰传媒 \\
\hline 债务资本成本率 & $6.40 \%$ & $6.40 \%$ & $6.40 \%$ \\
\hline 债务资本市值/总市值 & 0.33 & 0.27 & 0.31 \\
\hline 所得税税率 & 0 & 0 & 0 \\
\hline 股本资本成本率 & $13.17 \%$ & $11.28 \%$ & $12.64 \%$ \\
\hline 股本资本市值/总市值 & 0.67 & 0.73 & 0.69 \\
\hline 加权平均资本成本率 & $10.95 \%$ & $9.96 \%$ & $10.73 \%$ \\
\hline
\end{tabular}

注: 到 2013 年 12 月 31 日, 3 家出版上市公司均享受免征所得税 的优惠税率。

从表 6 中, 可以看出 2013 年, 3 家上市公司的债务资 本成本率和股本资本成本率都相差不大, 而且在债务资本 成本率低于股权资本成本率的条件下, 如果 3 家上市公司 能增加债务资本市值与总市值的比例, 也就是提高借债的 水平, 那么加权平均资本成本率将会显著的下降。

\section{5. 启示与思考}

通过上述分析, 可以看出, 出版上市公司想要实现资 本保值增值, 为股东创造更多的财富, 可以从以下几个方 面来提高经济增加值。

\section{（一）积极投资高收益资产，优化资产结构}

出版上市公司应改变现金持有量过高的现状, 积极物 色收益率更高的投资项目, 改变现在利息收入过高的局面, 切实从损害股东权益价值的资产配置结构转变为增加股东 权益价值的资产配置结构。

（二）多出畅销图书, 合理管理库存图书, 降低存货 跌价准备

出版上市公司应积极贴合市场, 多出畅销图书, 加快 图书存货的周转率, 合理管理目前的图书存货, 必要时可 以一次性对滞销图书提取减值准备, 切实降低存货跌价准 备，以降低投入资本的数量。

（三）优化融资结构, 降低加权平均资本成本

加权平均资本成本率与企业融资结构和融资方式有紧
密的关系, 出版企业应积极开展多种融资方式, 在充分考 虑债务融资的风险的基础上，适当提高财务杜杆率，提高 企业的负债率, 发挥财务杜杆的作用, 积极拓宽融资渠道, 降低加权平均资本成本率。

\section{参考文献(References)}

[1] S. O'Byrne, "EVA and Market Value," Journal of Applied Corporate Finance, vol. 10, no. 4, pp. 116-125, 1996.

[2] J. Wallace, "Adopting residual income-based compensation plans: Evidence of Effects on Management Actions," Journal of Accounting and Economics, vol. 24, pp. 58-72, 1996.

[3] S.M. Chen, and J. L. Dodd, "Economic Value Added: An Empirical Examination of a New Corporate Performance Measure ," Journal of Managerial Issue, vol. 9, pp. 318-333, 1997.

[4] S.R. Rajan, "Turning Capital to Wealth: A Banking of American," Utilities Public Utilities Fortnightly, vol. 22, pp. 36-46, 1999.

[5] I. Issham, A. Samad, M. Fazilah, Y. S. Hwa, and A. A. Kamil, "Economic Value Added (eva) as a Performance Measurement for glcs vs non-glcs: Evidence from Bursa Malaysia," Prague Economic Papers, vol. 2, pp. 168-179, 2008.

[6] H.Y. Wang, Y. Liu, H.Y. Fu, "Business Publisher Assessment Index System Research," Journal of Beijing Institute of Graphic Communication, vol. 5, pp. 54-56, 2007.

[7] G.Y. Wang, "Exploration on the Evaluation Index System of Performance Appraisal of Publishing House," Chinese Public Administration, vol. 5, pp. 29-31, 2009.

[8] Z.C. Yin, L. Wang, “The Performance Evaluation Index System of the Public Publication Service: Comparison, Pattern and Model," Science-Technology \& Publication, vol. 4, pp. 80-83, 2011.

[9] P. Wen, Y.Q. Wang, "Performance Appraisal of Publishing House Based on the balanced scorecard theory: A Case from $\mathrm{H}$ Publishing House," Publishing Research, vol. 4, pp. 52-56, 2012.

[10] S. Tang, "Performance comprehensive Evaluation on Listed Publishing Companies of Our Country," Publishing Research, vol. 8, pp. 5-10, 2010. 